\title{
Measurements of Laminar Flame Velocity for Components of Natural Gas
}

\author{
Patricia Dirrenberger ${ }^{1}$, Hervé Le Gall ${ }^{1}$, Roda Bounaceur ${ }^{1}$, Olivier Herbinet ${ }^{1}$, \\ Pierre-Alexandre Glaude ${ }^{1, *}$, Alexander Konnov ${ }^{2}$, Frédérique Battin-Leclerc ${ }^{1}$ \\ ${ }^{1}$ Laboratoire Réactions et Génie des Procédés, Nancy Université, CNRS, ENSIC, BP 20451, 1 Rue \\ Grandville, 54001 Nancy, France \\ ${ }^{2}$ Division of Combustion Physics, Lund University, Lund, Sweden
}

\begin{abstract}
This paper presents new experimental measurements of the laminar flame velocity of components of natural gas, methane, ethane, propane, and $n$-butane as well as of binary and tertiary mixtures of these compounds proposed as surrogates for natural gas. These measurements have been performed by the heat flux method using a newly built flat flame adiabatic burner at atmospheric pressure. The composition of the investigated air/hydrocarbon mixtures covers a wide range of equivalence ratios, from 0.6 to 2.1 , for which it is possible to sufficiently stabilize the flame. Other measurements involving the enrichment of methane by hydrogen (up to $68 \%$ ) and the enrichment of air by oxygen (oxycombustion techniques) were also performed. Both empirical correlations and a detailed chemical mechanism have been proposed, the predictions being satisfactorily compared with the newly obtained experimental data under a wide range of conditions.
\end{abstract}

\author{
Corresponding author \\ E-mail: pierre-alexandre.glaude@ensic.inpl-nancy.fr. \\ Phone: 33383175101.
}

Fax: 33383378120 . 


\section{Introduction}

Laminar burning velocities are important parameters in many areas of combustion science such as the design of burners and the prediction of explosions. They also play an essential role in determining several important aspects of the combustion process in spark ignition engines. The atmospheric issues and the problem of finite oil reserves have led to an enhanced interest for the use of natural gas in combustion engines and power generation systems. The main hydrocarbon included in natural gas is methane, with smaller amounts of heavier compounds, mainly hydrocarbons from $C_{2}$ to $C_{4}$. The fraction of heavier hydrocarbons can significantly vary depending on the source of natural gas, e.g., from 2 to $17 \%$ by volume (1).

The laminar flame velocities of methane/air, ethane/air, and propane/air mixtures have already been investigated in the three types of apparatus which are currently available for this type of measurement: (a) constant volume bombs (e.g., refs 2-6) in which the propagation of a flame is initiated by two electrodes and followed by shadowgraphy, (b) counterflow-flame burners (e.g., refs 7-12) with axial velocity profiles determined by particle imaging velocimetry (PIV), (c) flat flame adiabatic burners (e.g., refs 13-18), which consist of a heated burner head mounted on a plenum chamber with the radial temperature distribution measurement made by a series of thermocouples (this is the method used in this work).

Both constant volume bomb and counterflow flame burner do not allow a direct laminar burning velocity measurement but need an extrapolation to correct the stretch influence. It has been shown that a nonlinear extrapolation to zero stretch gave a more accurate results than older methods (e.g., 6 and 9), which could overestimate the velocity by $2 \mathrm{~cm} / \mathrm{s}$. Data published since the end of the $1990 \mathrm{~s}$ are the most reliable.

There is much less data about n-butane. Warnatz(19) reported some values in 1984 . Since then only three experimental studies have been published by Davis and Law (counterflow-flame burner) (9), by Hirasawa et al. (20) (counterflow-flame burner), and by Bosschaart and De Goey (flat flame adiabatic burner) (17).

While the influence of the content in $C_{2}$ to $C_{4}$ compounds can be of importance for the reactivity of natural gas, only a few papers deal with the laminar flame velocity of mixtures containing these species. In 2004, Liao (21) reported some values about the laminar flame velocity of a Chinese natural gas (96.2\% (vol) $\mathrm{CH}_{4}, 1.1 \% \mathrm{C}_{2} \mathrm{H}_{6}, 0.1 \% \mathrm{C}_{3} \mathrm{H}_{8}, 2.5 \% \mathrm{CO}_{2}$, and $0.1 \%$ others). In 2006 , Huang (22) studied the same gas then enriched with hydrogen (from $0 \%$ to $100 \%$ ). Previous data about the enrichment of methane by hydrogen were published by Yu et al. in 1986 for compositions ranging from $10 \%$ to $50 \% \mathrm{H}_{2}$ using the counterflow-flame method (23). In 2005, Halter et al. studied two compositions $\left(10 \% \mathrm{H}_{2}\right.$ and $\left.20 \% \mathrm{H}_{2}\right)(24)$, and in 2009 , Hu et al. reported results for $\mathrm{H}_{2}$ content ranging from $0 \%$ to $100 \%$ (26); both studies were performed using the combustion bomb method. Other measurements were performed for $\mathrm{H}_{2}$ content up to $35 \%$ by Coppens in 2007 (25) and then up to $40 \%$ by Hermanns in 2010 (27), both using the heat flux method.

The oxycombustion techniques rely on the use of pure oxygen as oxidizer rather than air. It strengthens flame stability and resistance to quenching, increases heat release, and reduces NOx emissions. It is of particular importance in the study of $\mathrm{CO}_{2}$ capture because of the high purity of $\mathrm{CO}_{2}$ produced, the after-treatment of which becomes easier. Nevertheless, apart from results from 1934 mentioned in ref 28 , there is only one recent study in literature regarding measurements of flame velocities with an enrichment of air by oxygen (29).

This work presents new results about the laminar flame velocity of methane, ethane, propane, and nbutane as well as of binary and tertiary mixtures of these compounds, measured using the heat flux 
method. The enrichment by hydrogen and by oxygen has also been studied with $\mathrm{H}_{2}$ content up to $68 \%$ and $\mathrm{O}_{2}$ mole fraction in the oxidizer gas from 0.21 (air) to 0.35 . These new experimental results have allowed the determination of new correlations. Simulations performed using a detailed kinetic model (31) are in correct agreement with these new data.

\section{Experimental Section}

In 1993, the heat flux method was introduced for the first time by de Goey and co-workers (13) in order to stabilize adiabatic flat flames and to measure adiabatic burning velocities. Since then a lot of work has been performed to improve the method and to build an ever more efficient burner (14-17) so that it is possible to study flat adiabatic flames which are very close to reference flames. With this method, contrary to the measurements performed using a constant volume bomb or a counterflowflame burner, there is no need for afterward correction to take into account the stretch effect.

In the present work, laminar burning velocities measurements were performed using a newly built flat flame adiabatic burner, i.e., according to the heat flux method previously quoted, as it can be seen in Figure 1. The design of the burner proposed by de Goey $(13,14)$ and used by Konnov $(15,16)$ was used. The apparatus consists of a burner head mounted on a plenum chamber. The burner head is a $2 \mathrm{~mm}$ thick perforated plate made of brass of $30 \mathrm{~mm}$ diameter which is used to stabilize the flame. Each small hole of the plate has a $0.5 \mathrm{~mm}$ diameter and the pitch between the holes is 0.7 $\mathrm{mm}$. Eight type $\mathrm{K}$ thermocouples of $0.5 \mathrm{~mm}$ diameter are soldered into the plate surface and are positioned at different distances and angles from the center to the periphery of the burner. The outer edge of the burner plate is heated at $353 \mathrm{~K}$ with thermostatic water to keep the temperature of the burner plate constant and to heat up the mixture when it flows through the plate at a higher temperature than the fresh gas mixture. The plenum mixing chamber located above the burner has a separate cooling system supplied with water at a temperature of $298 \mathrm{~K}$ in order to control the temperature of the fresh gas. Thus, the heat gain of the unburned gas mixture can compensate for the heat loss necessary for stabilizing the flame, knowing that the measurement of the heat loss or gain is performed using thermocouples.

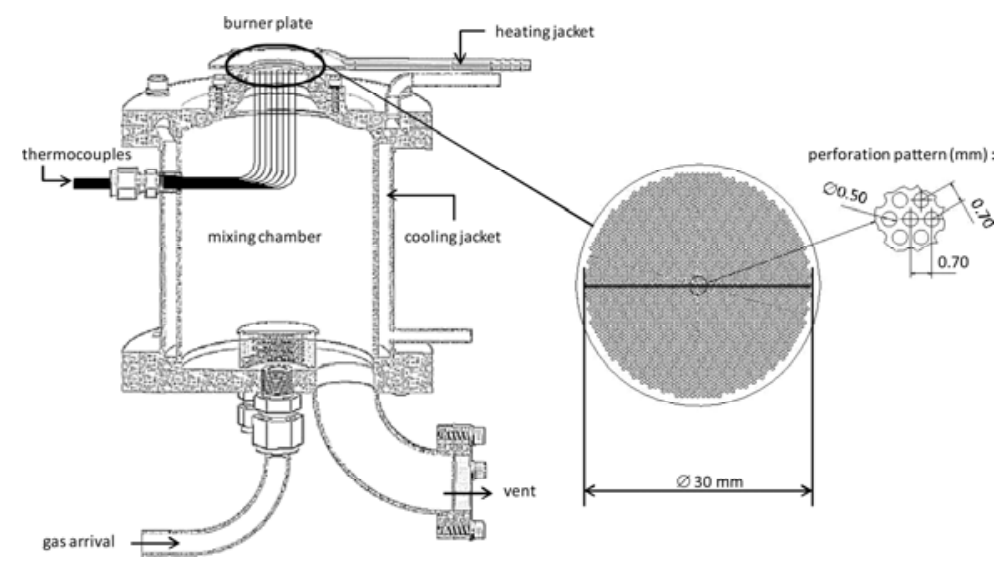

Figure 1. Scheme of the burner.

If the gas velocity is lower than the adiabatic flame burning velocity, the sum of the heat loss and heat gain is larger than zero. Then, the flame is stabilized under subadiabatic conditions, closer to the burner, and the center of the burner plate is hotter than the periphery. On the other hand, if the unburned gas velocity is larger than the adiabatic burning velocity, the flame is stabilized under superadiabatic conditions further from the burner, and the center of the burner plate is cooler than the periphery. When the temperature profile is flat, it means that the heat loss from the flame to the burner is exactly compensated by the heat flux from the burner to the fresh gases, and consequently 
that the flame is adiabatic. By changing the flow rate of the fresh gas mixture, it is possible to find the appropriate value of the gas velocity to cancel out the net heat flux so that the radial temperature distribution in the burner plate is uniform. The flow rate at which the net heat flux is zero corresponds to the adiabatic flame burning velocity.

The complete experimental setup (see Figure S1 in the Supporting Information) consists of a mixing panel which is assembled to supply gases from gas arrivals to the plenum chamber. In this way, there are five ducts: three for the fuels, one for the oxidizer, and one for the diluent gas. Each duct is connected to its own gas arrival and is equipped with a Bronkhorst High-Tech Mass Flow Controller (MFC) to regulate the gas flow. Note that for some equivalence ratios, it was necessary to use two MFCs to provide the flow of oxygen. As it has been previously mentioned, two thermostatic water baths provide the water to the heating and cooling jackets of the burner. Measurement of the temperature distribution is based on differences between each pair of neighbor thermocouples connected as an electrical circuit of two wires and the burner plate. Gases were delivered by Messer and Air Liquide, and their characteristics are given in the Supporting Information (Table S1).

As the adiabatic laminar flame velocity is found when the net heat loss is zero, the error is only dependent on a few factors. The error in the laminar flame velocity can be attributed to the error in the mass flow measurements (around $0.5 \%$ for each MFC) which can lead to a global error of $1.5 \%$ in the laminar flame velocity, the error in the reading of the temperature with thermocouples which could lead to an error of around $0.2 \mathrm{~cm} / \mathrm{s}$ in the laminar flame velocity, and to errors due directly to flame distortions, such as edge effects, for example (around $0.2 \mathrm{~cm} / \mathrm{s}$ ). Concerning the determination of equivalence ratios, note that the main error is due to the error in the mass flow measurements which leads to an error of about $1 \%$. Finally, there are some qualitative errors which are difficult to evaluate such as the possible errors in the fresh gas temperature if the gaseous mixture does not spend enough time in the plenum chamber to uniformly reach the temperature of $298 \mathrm{~K}$. Possible errors in the fuel purity are really tiny since high-purity gases are used (see Table S1 in the Supporting Information).

\section{Experimental Results}

The apparatus described above was used to study the laminar flame velocity of four hydrocarbons which are present in natural gas: methane, ethane, propane, and n-butane. Experiments were performed at $298 \mathrm{~K}$, at atmospheric pressure and using synthetic air ( $79 \%(\mathrm{vol}) \mathrm{N}_{2}$ and $\left.21 \% \mathrm{O}_{2}\right)$. Then, three different surrogate mixtures were chosen to represent natural gases from various origins because of their low content in other species (higher hydrocarbons, $\mathrm{CO}_{2}$, sulfur compounds...) and because they are different enough regarding their methane content. Finally, new experiments concerning enrichment of methane by hydrogen and enrichment of air by oxygen were performed to highlight the influence of the addition of these species in the gaseous mixture on the laminar flame velocity.

\subsection{Laminar Flame Velocity of Pure Compounds}

Methane, ethane, propane, and butane are all gaseous at $298 \mathrm{~K}$ and atmospheric pressure. Methane is the gas the laminar flame velocity of which has been the most studied $(4,6,10,11,14,15,18)$ since it is a reference gas for combustion studies and the major compound of natural gases. The velocities of ethane $(3,7,8,10,12,16,18)$ and propane $(2,3,5,7,8,10,12,17)$ have been slightly less studied, particularly with the heat flux method, although their presence can have a significant impact for natural gases flame velocities prediction. Finally, the velocity of $n$-butane has been much less studied than those of the three previous compounds $(9,17,19,20)$. 
$\mathrm{n}$-Butane is present much less in natural gases or in negligible amounts. Results concerning these four pure compounds are important for the study of mixtures representative of natural gases. A table of the experimental values obtained for the laminar burning velocities of these four compounds with the associated errors (corresponding to error bars in the related figures) is available in the Supporting Information (Table S2). Each experiment has been performed three times in order to test the reproducibility of the experiments. The overall accuracy of the burning velocity measurements takes into account a statistical error which was estimated thanks to a statistic law with $97.5 \%$ confidence level on the three measurements, associated with a systematic error estimated as previously described.

\subsubsection{Methane}

Figure 2a presents the evolution of the experimental laminar burning velocity of methane/air flames with an equivalence ratio. As the gas for which the largest number of experimental studies concerning its laminar flame velocity is available, methane is then the most appropriate pure compound to validate our newly built experimental setup. Note that it is the hydrocarbon laminar flame velocity of which is the lowest with a maximum of about $38 \mathrm{~cm} / \mathrm{s}$ for an equivalence ratio of 1.1. With methane, it was possible to measure a laminar flame velocity in an equivalence ratio range from 0.7 to 1.7. The results obtained with our apparatus are in good agreement with experimental data from the literature as shown in Figure 2a, particularly for lean mixtures. When the mixture is rich (above 1.2), there is a more significant difference with recent literature data. Although one might think that the real equivalent ratio in flat flames, especially in rich mixtures, may be affected by the entrainment of the ambient air, it had been tested and reported that it was not the case, at least for an equivalence ratio up to $1.5(15,16)$.
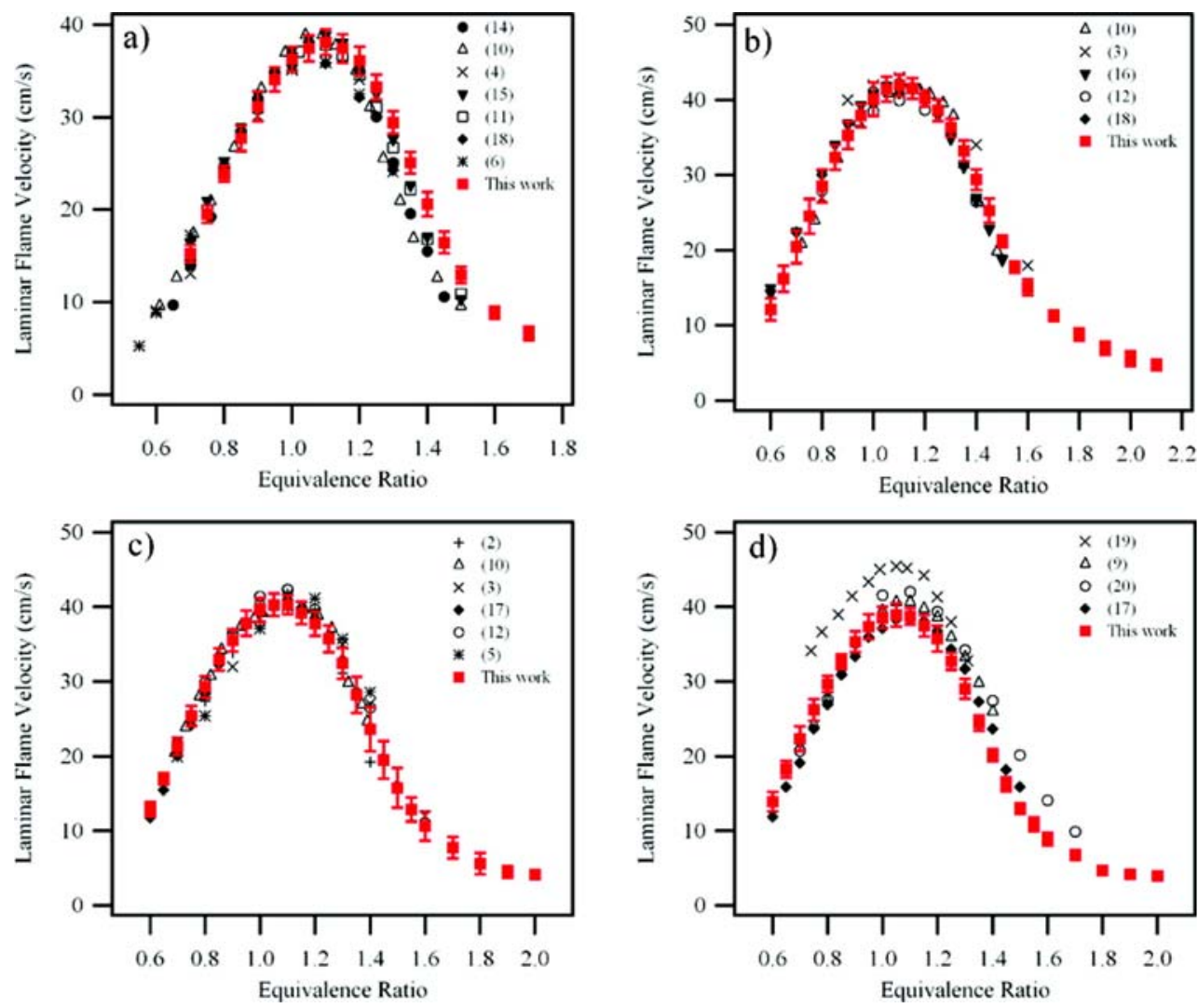

Figure 2. Measurement of the laminar burning velocity as a function of equivalence ratio for pure hydrocarbon/air mixtures: (a) methane, (b) ethane, (c) propane, (d) butane (solid symbols = heat flux method; open symbols = counterflow method; crosses = combustion bomb method) . 


\subsubsection{Ethane}

Contrary to methane, ethane is the hydrocarbon corresponding to the highest laminar flame velocity with a maximum of $42 \mathrm{~cm} / \mathrm{s}$ for an equivalence ratio of 1.1. It was possible to perform experiments over a wider range of equivalence ratios (from 0.6 to 2.1), since it was much easier to stabilize a flame of ethane than of methane. The results are plotted in Figure $2 \mathrm{~b}$. For ethane, there are also many results in the literature, and the results obtained in this work are in good agreement with them.

\subsubsection{Propane}

Measurements of laminar flame velocities of propane were also investigated. The maximum obtained at an equivalence ratio of 1.1 is around $40 \mathrm{~cm} / \mathrm{s}$, and the propane profile is located between those of methane and ethane. Like for ethane, it was possible to cover a wide range of equivalence ratios, from 0.6 to 2.0. The experimental data obtained during this work are in good agreement with those of literature as shown in Figure 2c.

\subsection{4. n-Butane}

The $\mathrm{n}$-butane is the last pure compound which was studied in this work. The maximum is around 39 $\mathrm{cm} / \mathrm{s}$, just between methane and propane. Since the $\mathrm{n}$-butane flame could be easily stabilized, it has been possible to cover an equivalence ratio range from 0.6 to 2.0. Another MFC has been added for oxygen for equivalence ratios 1.0 and 1.05 . Contrary to the three alkanes previously considered, there are only a few experimental data available in the literature. The results obtained in this work are in good agreement with those measured by Bosschaart et al. (17) as shown in Figure $2 \mathrm{~d}$. Note that the maximum is closer to an equivalence ratio of 1.05 than to one of 1.1.

\subsection{Laminar Flame Velocity of Hydrocarbons Mixtures}

The study of pure compounds has provided useful data. However, it is important to study mixtures and especially binary and tertiary mixtures. First, natural-gas surrogate mixtures have been investigated.

As shown in Table 1, the composition of natural gases depends on its origin. As an example, the natural gas from North Sea is mainly composed of methane $(95.7 \%)$ and ethane $(3.55 \%)$, whereas the natural gas from Abu Dhabi contains $82.07 \%$ of methane, $15.86 \%$ of ethane, and $1.89 \%$ of propane. Some natural gases not only contain hydrocarbons but also species such as nitrogen, carbon dioxide, and sulfur compounds. In this work, we only studied the influence of the amount of ethane and propane along with methane on the laminar flame velocity.

An additional study has been carried on methane-ethane mixtures considering the variation of ethane content in the fuel mixture at different equivalence ratios (from 0.7 to 1.5 ).

\subsubsection{Natural Gas Surrogate Mixtures}

For the present work, we have chosen three surrogate mixtures with compositions as close as possible to those of three representative natural gases: Pittsburgh, Abu Dhabi, and Indonesia (bold columns in Table 1). These natural gases were represented by the following mixtures: $85 \% \mathrm{CH}_{4}$ and $15 \% \mathrm{C}_{2} \mathrm{H}_{6}$ for Pittsburgh, $82 \% \mathrm{CH}_{4}, 16 \% \mathrm{C}_{2} \mathrm{H}_{6}$, and $2 \% \mathrm{C}_{3} \mathrm{H}_{8}$ for Abu Dhabi, and $90 \% \mathrm{CH}_{4}, 6 \% \mathrm{C}_{2} \mathrm{H}_{6}$, and $4 \% \mathrm{C}_{3} \mathrm{H}_{8}$ for Indonesia. Table 1 shows the composition of different natural gases and thus the real composition of those mentioned above. 
Table 1. Composition of Different Natural Gases (\% Volume) According to Lamoureux and Paillard (1)

\begin{tabular}{|c|c|c|c|c|c|c|c|c|c|c|}
\hline & $\begin{array}{l}\text { Frigg } \\
\text { (North } \\
\text { Sea) } \\
\end{array}$ & $\begin{array}{c}\text { Lacq } \\
\text { (France) }\end{array}$ & $\begin{array}{l}\text { Urengoï } \\
\text { (Russia) }\end{array}$ & $\begin{array}{c}\text { Hassi } \\
\text { R'Mel } \\
\text { (Algeria) }\end{array}$ & $\begin{array}{l}\text { Abu } \\
\text { Dhabi } \\
\text { (UAE) }\end{array}$ & Indonesia & $\begin{array}{l}\text { Matheson } \\
\text { (Ontario) }\end{array}$ & $\begin{array}{c}\text { Groningue } \\
\text { (Netherlands) }\end{array}$ & $\begin{array}{c}\text { Abu } \\
\text { Madhi } \\
\text { (Egypt) }\end{array}$ & $\begin{array}{c}\text { Pittsburgh } \\
\text { (USA) }\end{array}$ \\
\hline $\mathrm{CH}_{4}$ & 95.7 & 69.2 & 98 & 83.5 & 82.07 & 89.91 & 96.62 & 81.3 & 92.8 & 85 \\
\hline $\mathrm{C}_{2} \mathrm{H}_{6}$ & 3.55 & 3.5 & & 7.9 & 15.86 & 5.44 & 2.32 & 2.9 & 4.1 & 14 \\
\hline $\mathrm{C}_{3} \mathrm{H}_{8}$ & 0.04 & 1.1 & & 2.1 & 1.89 & 3.16 & 0.54 & 0.4 & 1.2 & \\
\hline i- & 0.01 & 0.7 & & 1 & & 1 & & 0.2 & & \\
\hline \multicolumn{11}{|l|}{$\mathrm{C}_{4} \mathrm{H}_{10}$} \\
\hline$n-$ & & & & & 0.06 & 0.75 & 0.12 & & & \\
\hline \multicolumn{11}{|l|}{$\mathrm{C}_{4} \mathrm{H}_{10}$} \\
\hline$i-$ & & & & & & 0.03 & & & & \\
\hline \multicolumn{11}{|l|}{$\mathrm{C}_{5} \mathrm{H}_{12}$} \\
\hline $\mathrm{CO}_{2}$ & 0.3 & 9.3 & 0.8 & 0.2 & & & & 0.9 & 0.7 & \\
\hline $\mathrm{N}_{2}$ & 0.4 & 0.6 & 1.2 & 5.3 & 0.05 & 0.04 & 0.3 & 14.3 & 0.4 & 1 \\
\hline others & & 15.3 & & & & & & & & \\
\hline
\end{tabular}

Figure 3a shows the results obtained for the three natural gas surrogates. These experimental data show that the profiles for the three surrogates lie in between those of methane and ethane. Note that the methane content seems to determine the laminar flame velocity. Indeed, the propane content is not of great importance as there is not a significant difference between Pittsburgh and Abu Dhabi gases. While the flame velocity profiles stand between those of pure methane and ethane, they are much closer to the methane profile. A table of the experimental values obtained for the laminar burning velocities of these mixtures with the associated errors is available in the Supporting Information (Table S3).
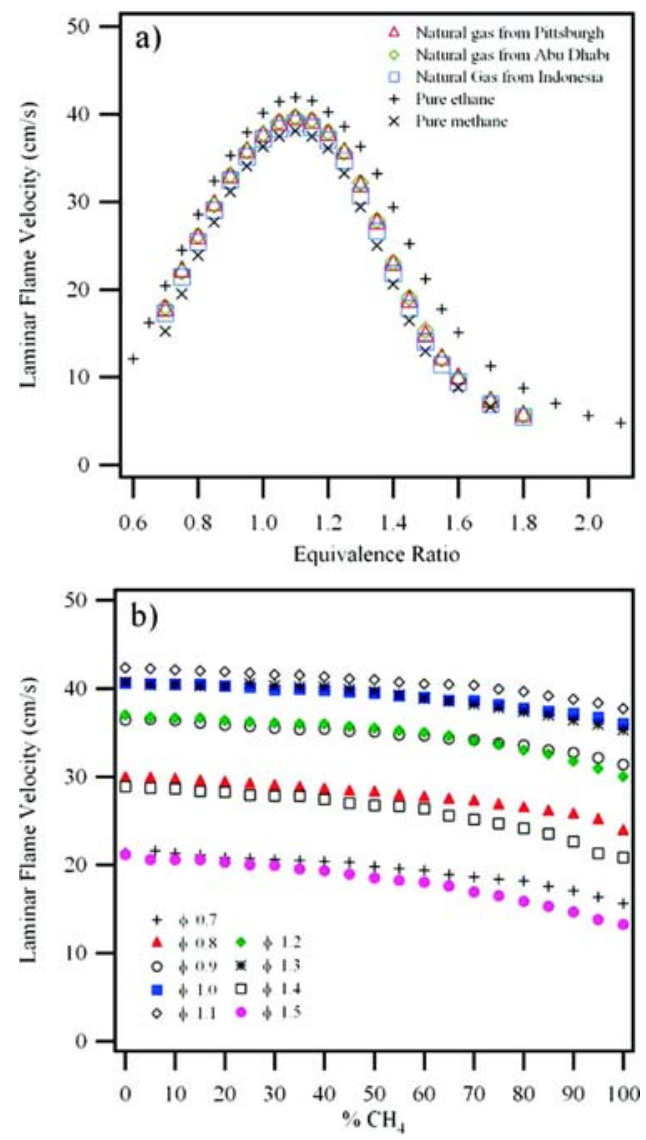

Figure 3. Measurement of the laminar burning velocity (a) as a function of equivalence ratio for natural gas/air mixtures and (b) as a function of methane content relative to ethane for a methaneethane/air mixture. 


\subsubsection{Methane-Ethane Mixtures in Different Proportions}

In order to complete the study of hydrocarbons mixtures, methane-ethane mixtures were investigated and experiments were performed by considering the variation in the amount of ethane relative to that of methane in the mixture. Figure $3 \mathrm{~b}$ presents the variations of the laminar flame velocities with the mole fraction of $\mathrm{CH}_{4}$ in the binary mixture from 0 to $100 \%$ for equivalence ratios ranging from 0.7 to 1.5 . For all equivalence ratios, these variations are linear at least until $50 \%$ of $\mathrm{CH} 4$, and then the decrease of the flame velocity with the increase of the $\mathrm{CH}_{4}$ content is more pronounced, particularly for rich mixtures.

\subsubsection{Laminar Flame Velocity of Hydrogen-Enriched Methane Mixtures}

While it is possible to find many results concerning the measurement of laminar flame velocities for diluted methane (in nitrogen, helium, argon...), only a few papers deal with the measurement of laminar flame velocities of methane mixtures enriched by hydrogen (23-27), which can be of significant importance as it leads to a significant increase in flame velocity.

Figure 4a shows the variation of laminar flame velocities with equivalence ratios obtained for different hydrogen contents in the fuel mixture. It appears that the enrichment by hydrogen significantly increases the adiabatic laminar burning velocity. This increase of the laminar burning velocity becomes more important when the hydrogen content in the mixture rises. Note that, when the hydrogen content exceeds $50 \%$, the maximum of the curve is observed for an equivalence ratio of 1.15 instead of 1.1. It has been somewhat difficult to perform measurements for 60 and $67 \%$ of $\mathrm{H}_{2}$ due to the growing instability of the flame. For these measurements, at an equivalence ratio close to 1.5 , acoustic instabilities were observed.

In order to better observe the increase in flame velocity, additional measurements were carried out for an equivalence ratio of 1.1 , for which it was possible to reach an enrichment of $68 \%$ of $\mathrm{H}_{2}$, knowing that the limitation here is mainly due to the range of the MFCs. In Figure 4b, measured laminar burning velocities are presented as a function of the hydrogen content for an equivalence ratio of 1.1 and these results are compared to those of the literature (23-27). Our measurements are in good agreement with these data, at least with those which have been recently obtained (24-27). The agreement is very good from 0 to $68 \%$ of $\mathrm{H}_{2}$ with the results of the only study in which such a large $\mathrm{H}_{2}$ content has been used (26).

\subsubsection{Enrichment of Air by Oxygen}

Figure 5 presents results obtained for laminar flame velocities of methane with an enrichment of air by oxygen. In this case, results are presented as a function of $D$, which is defined as follows

$$
\mathrm{D}=\frac{\mathrm{Q}_{\mathrm{O}_{2}}}{\mathrm{Q}_{\mathrm{O}_{2}}+\mathrm{Q}_{\mathrm{N}_{2}}}
$$

where $Q_{i}$ is the volumetric flow rate of compound $i$. Thus, when experiments are performed with synthetic air, as in Figure 2a, for example (results reported in Figure 5), D = 0.21. The increase in flame velocity is much faster than in the case of the enrichment with hydrogen. That is why it was only possible to carry out measurements up to $D=0.35$ but not beyond since the laminar burning velocity was already close to $130 \mathrm{~cm} / \mathrm{s}$ for an equivalence ratio of 1.0. Results are in good agreement with those of the only other study (29) performed in a narrower range of equivalence ratios. Note that, when the amount of oxygen in the mixture increases, the maximum of the curve moves gradually closer to 1.0 instead of 1.1. For high burning velocities (e.g., $100-200 \mathrm{~cm} / \mathrm{s}$ ), some distortions of the 
flame cannot be excluded and a solution to this problem could be to reduce the diameter of the holes of the perforation.(14) However the agreement with the data of Shin et al.(29) obtained using the Bunsen nozzle flame technique is even for burning velocities up to $120 \mathrm{~cm} / \mathrm{s}$.
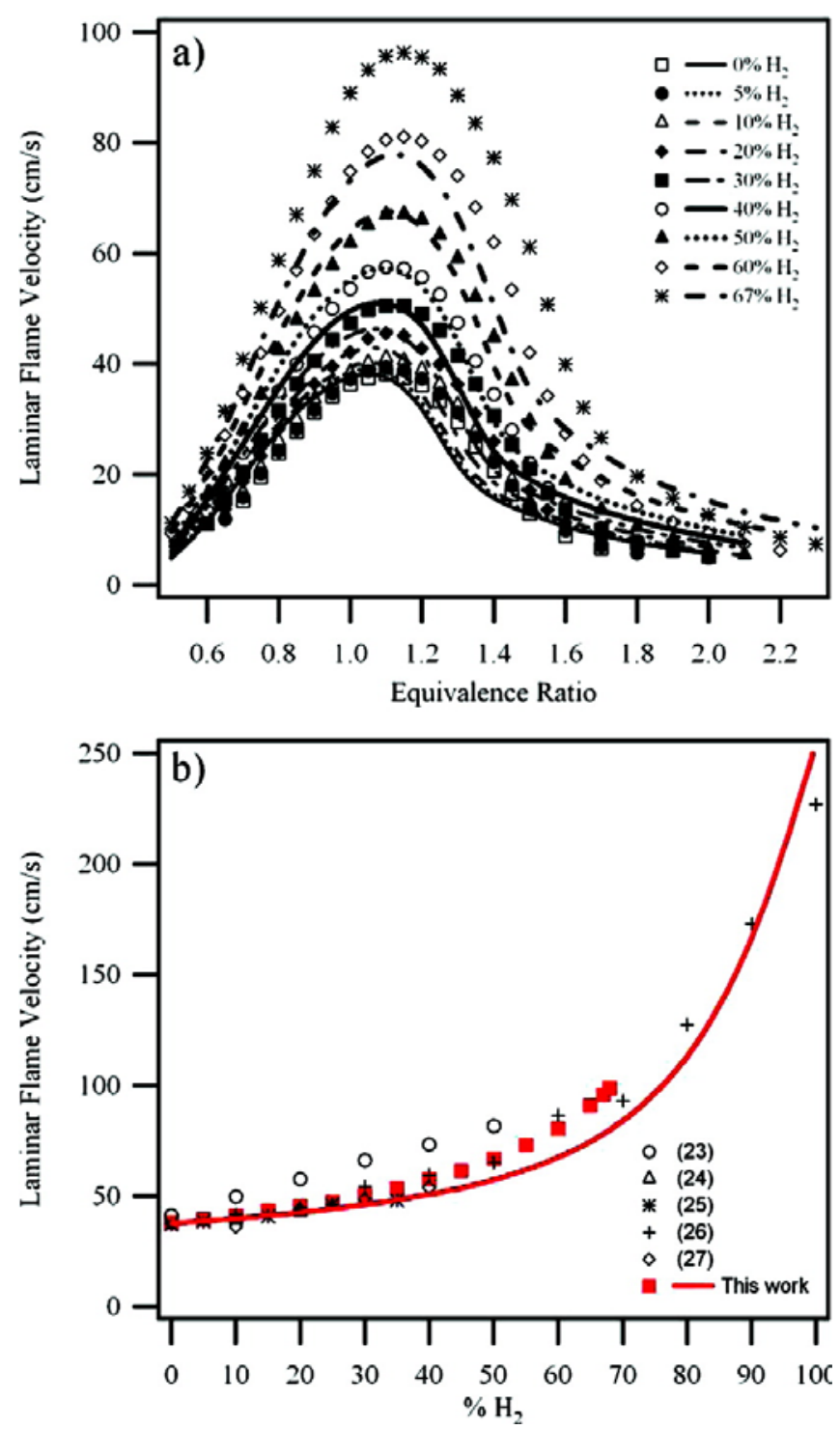

Figure 4. Laminar burning velocities (a) as a function of equivalence ratio for a methane- $\mathrm{H}_{2} /$ air mixture and (b) as a function of hydrogen content relative to methane for a methane- $\mathrm{H}_{2} /$ air mixture at an equivalence ratio of 1.1. Symbols, experiments; lines, modeling. 


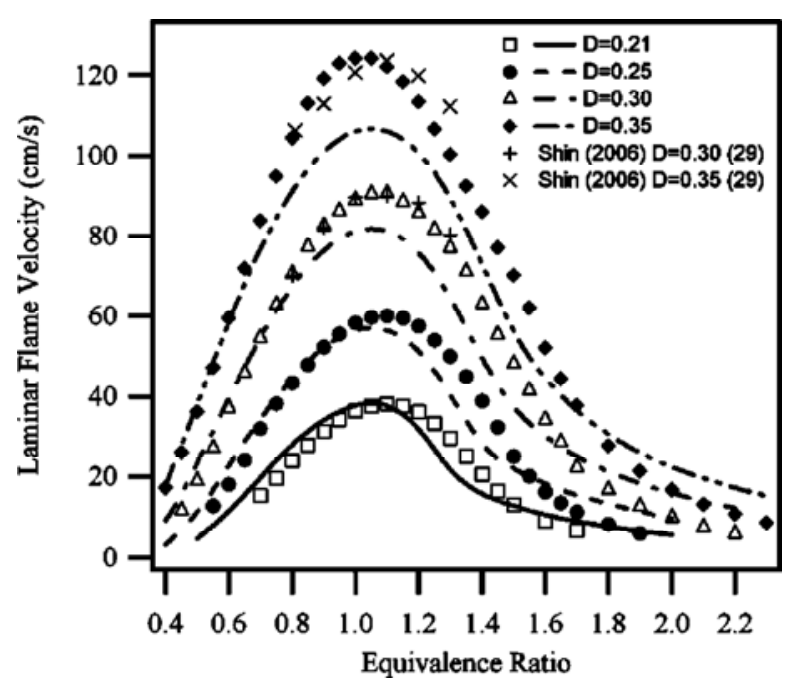

Figure 5. Measurement of the laminar burning velocity as a function of equivalence ratio for an enriched by $\mathrm{O}_{2}$ methane/air mixture. Points, experiments; lines, modeling.

\section{Correlations}

By consideration of the previous experimental results, it was possible to propose correlations for the laminar burning velocities of hydrocarbons flames, not only for the pure compounds but also for the mixtures.

\subsection{Correlation for Pure Compounds}

In the case of pure compounds, the following correlation, which was proposed by Gülder (32) to predict laminar burning velocity of methane flames as a function of equivalence ratio $(\phi)$, has been used in this work:

$\mathrm{S}_{\mathrm{L}}=\mathrm{W} \varphi^{\eta} \mathrm{e}^{-\xi(\varphi-\sigma)^{2}}$

The parameters used in this correlation have been fitted from the measurements made in this work. The values of the obtained parameters are given in Table 2, together with parameters proposed in literature for the same type of correlation in the case of methane. Our parameters are very close to those found by Coppens et al. (25).

Table 2. Values of the Parameters Obtained for the Correlation in the Case of Pure Compounds

\begin{tabular}{ccccccc}
\hline & \multicolumn{2}{c}{ Gülder (32) } & \multicolumn{2}{c}{ Coppens et al. (25) } & \multicolumn{2}{c}{ present work } \\
parameter & methane & methane & methane & ethane & propane & butane \\
\hline$W(\mathrm{~cm} / \mathrm{s})$ & 42.2 & 39.0542 & 38.638 & 42.154 & 42.2012 & 41.1004 \\
$\eta$ & 0.15 & -0.4333 & -0.15 & 0.1099 & -0.3104 & -0.5964 \\
$\xi$ & 5.18 & 6.0157 & 6.2706 & 4.466 & 5.1455 & 5.3151 \\
$\sigma$ & 1.075 & 1.1 & 1.1 & 1.1 & 1.1 & 1.1 \\
\hline
\end{tabular}

The comparison between flame velocities estimated using these correlations and those experimentally measured are presented in Figure 6a for the methane and given in the Supporting Information for the other pure compounds (Figure S2), since the same behavior is observed. The fitting of the parameters were performed using a range of equivalence ratios between 0.6 ( 0.7 for methane) and 1.6. The fitting was not possible in the full range of equivalence ratios covered by the experiments. That is why the calculated results and the measured ones do not fully agree for $\phi>1.6$. Despite this consideration, there is a very good agreement between correlated results and experimental data. 

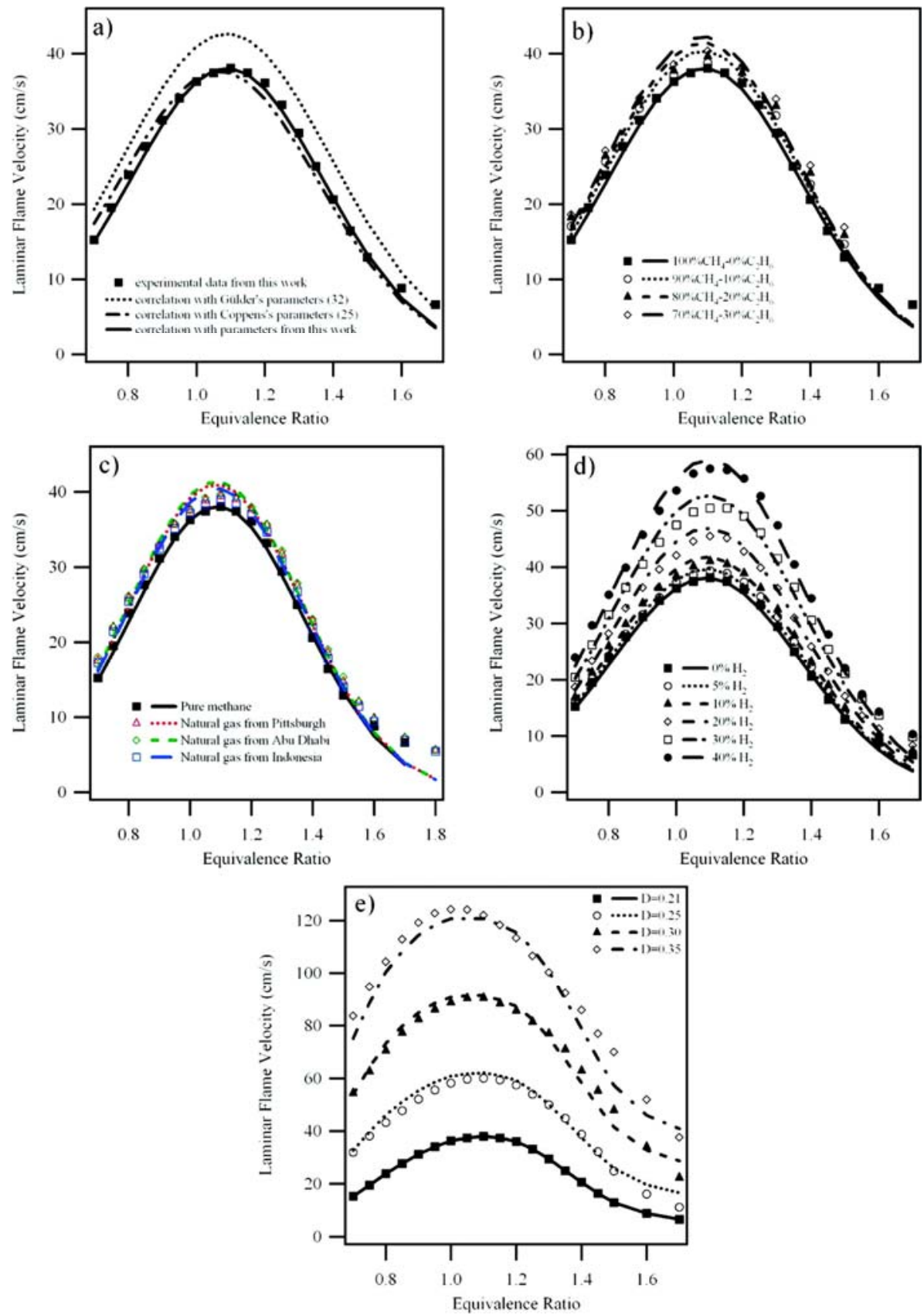

Figure 6. Correlation of the laminar burning velocity as a function of equivalence ratio for (a) a methane/air mixture, (b) methane-ethane/air mixtures, (c) natural gas surrogate/air mixtures, (d) methane-hydrogen/air mixtures, and (e) enriched by $\mathrm{O}_{2}$ methane/air mixtures. Points, experiments; lines, correlation.

\subsection{Correlation for Mixtures}

In the case of mixtures, it was not possible to use the same correlation as for pure compounds because it does not take into account the presence of another compound in methane. In fact, an additional parameter, a function of the amount of the other gas in the fuel mixture, had to be added. Moreover, it was also necessary to insert an additional term in the exponent in order to reproduce the shift of the maximum of the laminar flame velocity dependence with the additional gas concentration. 
Thus, we have used the following correlation proposed by Coppens et al. (25) for the mixtures of methane with another gas:

$\mathrm{S}_{\mathrm{L}}=\left(1+\gamma \alpha^{\tau}\right) \mathrm{W} \varphi^{\mathrm{n}} \mathrm{e}^{-\xi(\varphi-\sigma-\Omega \alpha)^{2}}$

with $\alpha$ the mole fraction of the additional gas in the fuel mixture.

Like for pure compounds, measurements from this work were used to fit the parameters of this correlation. All parameters obtained are listed in Table 3.

Table 3. Values of the Parameters Obtained for the Correlations in the Case of Binary Mixtures

\begin{tabular}{lllll}
\hline \multicolumn{1}{c}{ parameter } & \multicolumn{2}{c}{$\mathrm{CH}_{\mathbf{4}}+\mathbf{H}_{\mathbf{2}}$} & \multicolumn{1}{c}{$\mathbf{C H}_{\mathbf{4}}+\mathbf{C}_{\mathbf{2}} \mathbf{H}_{\mathbf{6}}$} & \multicolumn{2}{c}{$\mathbf{C H}_{\mathbf{4}}+\mathbf{C}_{\mathbf{3}} \mathbf{H}_{\mathbf{8}}$} & \multicolumn{1}{c}{$\mathbf{C H}_{\mathbf{4}}+\mathbf{H}_{\mathbf{2}}$} \\
\hline$\gamma$ & 1.9153 & 0.2103 & 0.2129 & 1.7365 \\
$\tau$ & 1.533 & 0.545 & 0.8312 & 1.2508 \\
$W(\mathrm{~cm} / \mathrm{s})$ & 39.0542 & 38.6385 & 38.6385 & 38.6385 \\
$\eta$ & -0.4333 & -0.15 & -0.15 & -0.15 \\
$\xi$ & 6.0157 & 6.2706 & 6.2706 & 6.2706 \\
$\sigma$ & 1.1 & 1.1 & 1.1 & 1.1 \\
$\Omega$ & 0.0133 & -0.0191 & -0.0439 & 0.0165 \\
\hline
\end{tabular}

\subsubsection{Correlation for Methane-Ethane Mixtures}

With the use of the previously mentioned eq 3 for mixtures, it is possible to obtain a correlation for the methane-ethane mixtures. Comparisons of correlated and experimental data for the laminar burning velocities of four methane-ethane mixtures are shown in Figure 6b. Contrary to Figure 3b, in Figure $6 \mathrm{~b}$ results are presented as a function of equivalence ratio. Correlated values are in satisfactory agreement with experimental ones, even if the agreement is not as good as that obtained for pure compounds. There is a good agreement for lean and rich mixtures, but the correlation overestimates flame velocities near stoichiometry. Note that the fitting of parameters was performed using experimental values for a range of equivalence ratios between 0.8 and 1.3.

\subsubsection{Correlation for Natural Gas Surrogate Mixtures}

With the use of measurements performed for methane-propane mixtures (see Figure S3 in the Supporting Information, which shows a similar behavior as for the methane-ethane mixture), the related correlation parameters have been determined and are given in Table 3. By combination of these results with those obtained for methane-ethane mixtures, the following correlation for ternary mixtures can be proposed:

$S_{L}=\left(1+\nu_{1} \alpha_{1}^{{ }^{\tau_{1}}}\right)\left(1+\nu_{2} \alpha_{2}{ }^{{ }_{2}}\right) W \varphi^{\eta} e^{-\xi\left(\varphi-\sigma-\Omega_{1} \alpha_{1}-\Omega_{2} \alpha_{2}\right)^{2}}$

with $\alpha_{1}$ and $\alpha_{2}$, the mole fractions of ethane and propane, respectively, in the fuel mixture, $\gamma_{1}, \tau_{1}, \Omega_{1}$, the parameters calculated for the methane-ethane mixture, and $\nu_{2}, \tau_{2}, \Omega_{2}$, the parameters calculated for the methane-propane mixture.

Flame velocities estimated using this correlation have been compared with the measurements made in this work for the three studied natural gas surrogate mixtures. Results are presented in Figure 6c. Correlation results are in good agreement with the experimental ones. As for methane-ethane mixtures, the agreement is better for lean and rich mixtures but less satisfactory close to stoichiometry. It is not surprising to observe the same behavior as in the previous case since the 
correlation for natural gas-like mixtures is based on the correlations for methane-ethane and methane-propane mixtures.

\subsubsection{Correlation for Methane-Hydrogen Mixtures}

The correlation (see eq 3) proposed by Coppens et al. (25) has also been used to correlate results for methane-hydrogen mixtures. The values obtained for the parameters are given in Table 3 . Correlated results are presented in Figure $6 \mathrm{~d}$ and show a good agreement with experimental values. Note that the parameters were fitted for a range of equivalence ratios between 0.7 and 1.4. This correlation is able to reproduce the experimental results only for $\mathrm{H}_{2}$ content up to $40 \%$ so that higher contents are not shown. Above this content, there is an important deviation between experimental and correlated results. The correlation is based on the properties of a methane flame, and when the hydrogen content in the mixture exceeds $50 \%$, the behavior and the properties of the flame are likely to be closer to those of a flame of pure hydrogen. Tahtouh et al. (30) have shown that the laminar burning velocity of methane/hydrogen mixtures evolves linearly with the mass of hydrogen. The same behavior has been found here: for stoichiometric mixtures in air, $\mathrm{S}_{\mathrm{L}}$ can be expressed as $35.70+$ $2.30 \mathrm{y} \mathrm{cm}^{-1}, \mathrm{v}$ being the mass percentage of hydrogen in the fuel. Tahtouh et al. proposed the correlation $33.96+1.83 \mathrm{y} \mathrm{cm}^{-1}$, reflecting the slightly lower experimental burning velocities measured by this team in comparison with the present work.

\subsubsection{Correlation for Methane/Oxygen-Enriched Air Mixtures}

In the case of methane/oxygen-enriched air mixtures, it was not feasible to use the previous correlation. Indeed, oxygen is not another combustible gas added to methane, such as hydrogen, for example. It is an oxidizer, and it is the air which is enriched by oxygen. Thus, correlation previously mentioned was no longer suitable.

The equation which is presented below is based on those of Hermanns et al. (27) but was rearranged to be appropriate for our case and our conditions:

$S_{L}=S_{L, 0}(1-A, E)$

where $S_{L, 0}$ is the experimental laminar burning velocity of pure methane, $A=z_{0}+z_{1} \phi+z_{2} \phi_{2}$, and $z_{0}$, $z_{1}$, and $z_{2}$ are fitting parameters. $E=(1-(D / 0.21))$ is the enrichment fraction, with $D=\left(Q_{02} /\left(Q_{02}+\right.\right.$ $\left.\mathrm{Q}_{\mathrm{N} 2}\right)$ ) as previously established by eq 1 .

As in the case of methane-ethane mixtures, calculations were performed using experimental values for a range of equivalence ratios between 0.8 and 1.3. $z_{0}, z_{1}$, and $z_{2}$ were found to be 21.081, -31.550 , and 13.919, respectively. A comparison between correlated and experimental results is presented in Figure 6e. The agreement is good, particularly for a range of equivalence ratios between 0.7 and 1.4.

\section{Simulations}

A detailed kinetic mechanism has been automatically generated by the computer package EXGAS (31) for a propane/n-butane mixture. The reaction mechanisms provided by EXGAS are made of three parts:

1) $A C_{0}-C_{2}$ reaction base, including all the reactions involving radicals or molecules containing less than three carbon atoms. The fact that no generic rule can be derived for the generation of the reactions involving very small compounds makes the use of this reaction base necessary. Note that 
the reactions of methane and ethane are included in this reaction base. The kinetic data used in this base were taken from the literature and are mainly those proposed by Baulch et al. (33) and Tsang et al. (34) The $\mathrm{C}_{0}-\mathrm{C}_{2}$ reaction base was first presented by Barbé et al. (35) and has continuously been updated (36). To obtain a good agreement for the simulation of methane flame velocities, the rate constant of the reaction between methyl radicals and oxygen has been multiplied by a factor of 10 , compared to the value proposed by Dagaut et al. (37) previously used. To obtain a good agreement for the simulation of ethane flame velocities, the low-pressure limit of the rate constant of the decomposition of ethyl radicals has been divided by 2 , compared to the value proposed by Baulch et al. (33).

2) A comprehensive primary mechanism, where the only molecular reactants considered are the initial organic compounds (here propane and $n$-butane) and oxygen. The following reactions are considered: (a) Unimolecular initiations involving the breaking of $\mathrm{C}-\mathrm{C}$ and $\mathrm{C}-\mathrm{H}$ bonds, (b) bimolecular initiations with oxygen to produce alkyl and $\bullet \mathrm{HO}_{2}$ radicals, (c) oxidations of alkyl radicals with $\mathrm{O}_{2}$ to form alkenes and $\bullet \mathrm{HO}_{2}$ radicals, (d) isomerizations of alkyl radicals, (e) decompositions of radicals by $\beta$-scission involving the breaking of $\mathrm{C}-\mathrm{C}$ or $\mathrm{C}-\mathrm{H}$ bonds, (f) metatheses involving $\mathrm{H}$ abstractions by radicals from the initial reactants, and ( $\mathrm{g}$ ) combinations of radicals. The fact that the additions of alkyl radicals to oxygen molecules and the subsequent reactions, which are only important below $1000 \mathrm{~K}$, are not considered allows the mechanisms to keep a limited size compatible with laminar flame velocity computations.

3) A lumped secondary mechanism that contains the reactions consuming the molecular products of the primary mechanism which do not react in the reaction base.

Thermochemical data for molecules or radicals were calculated and stored as 14 polynomial coefficients, according to the CHEMKIN formalism (38). These data were calculated using software THERGAS (39), based on the group and bond additivity methods proposed by Benson (40). The transport properties are used for the evaluation of gas-phase multicomponent viscosities, thermal conductivities, diffusion coefficients, and thermal diffusion coefficients and are defined in CHEMKIN format (38). For the species for which it was possible, we considered the values of transport data issued from the literature and common to many chemical models. For the other species, we have used a correlation based on molar mass proposed by Wang and Frenklach (41).

The Premix code from the CHEMKIN Collection (38) is used for the flame modeling. Multicomponent diffusion and thermal diffusion options were taken into account. The full mechanism involves 100 species and includes 829 reactions and is available on request. For the determination of the burning velocity, the convergence parameters in Premix were reduced progressively until an increase of the number of grid points does not change the numerical solution. Comparison of predicted and experimental results are given in Figure 7a for the four pure alkanes studied, in Figure $7 \mathrm{~b}$ for the natural gas surrogates (Figure S4 in the Supporting Information concerns methane/ethane mixtures), in Figure 4 for the $\mathrm{H}_{2}$ enrichment, and in Figure 5 for the $\mathrm{O}_{2}$ enrichment.

Simulations reproduce the main experimental trends. Note however that, in the case of methane, ethane, and natural gas surrogates, a shift of about 0.05 toward leaner mixtures is observed in a large part of the studied equivalence ratio range. This deviation is less pronounced for heavier alkanes and enriched mixtures. The maximum value of flame velocity are well predicted for methane, butane, natural gas surrogates but overestimated in the case of ethane and propane and underestimated in the case of enriched mixtures. If better results can be obtained in the case of methane and ethane using the model of Konnov (42), the same significant overprediction is observed for propane. Note that the nonlinear variation of flame velocity with the ethane content in methane/ethane mixtures is well modeled (see Figure S4 in the Supporting Information). The increasing of flame velocity with increasing $\mathrm{H}_{2}$ content experimentally shown by our results and those of Hu et al. (26) is also well reproduced by the model (see Figure $4 b$ ). 

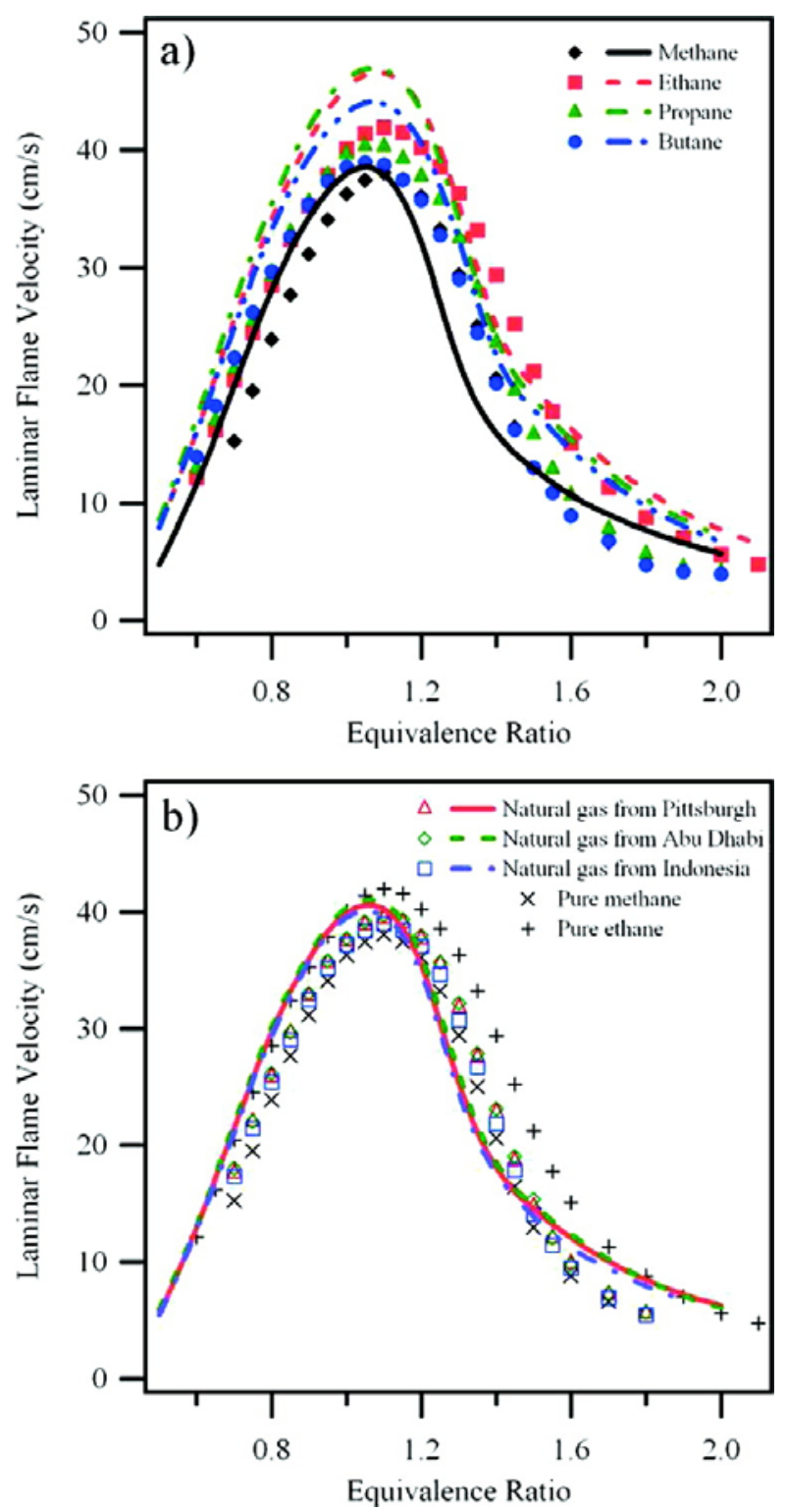

Figure 7. Laminar burning velocities as a function of equivalence ratio for (a) a hydrocarbon/air mixture and (b) a natural gas/air mixture. Points, experiments; lines, modeling.

\section{Conclusions}

A newly developed apparatus based on the heat flux method has been used for measuring adiabatic laminar burning velocities of hydrocarbons/air mixtures. After the validity of this apparatus was checked in the case of pure alkanes from methane to propane with very satisfactory comparisons with literature data, this study has allowed the obtaining new results over a wide range of equivalence ratios for the following mixtures: (a) n-butane/air mixtures, for which some dispersion were observed in literature data, (b) natural gas surrogates/air mixtures, for which very few previous measurements were available, (c) methane enriched in $\mathrm{H}_{2}$ /air mixtures (for $\mathrm{H}_{2}$ content up to $68 \%$ ), for which very few previous measurements were available for $\mathrm{H}_{2}$ content above $50 \%$, (d) methane/air enriched in $\mathrm{O}_{2}$ mixtures, for which only one previous study was available. In these last two cases, our measurements confirm the recent ones from the literature.

Empirical correlations have been deduced from the experimental results which allow the evaluation of the flame velocity of natural gases at $298 \mathrm{~K}$ under $1 \mathrm{~atm}$ from their chemical compositions. 
Correlations have also been proposed in the case of enriched mixtures. Finally, a detailed kinetic model has been generated using EXGAS software and has led to mostly satisfactory predictions for all the studied mixtures.

\section{Acknowledgment}

This work was funded by the Région Lorraine in the project "Procédés Propres et Développement Durable" of the Program "Matériaux-Energie-Procédés-Produits". The authors wish also to thank the COST Action Grant CM0901.

\section{Supplementary Material}

Scheme of the experimental setup, a comparison between correlations and experimental results not displayed in the main text, simulation of laminar burning velocities for the methane-ethane/air mixture, composition of the gases used, and table of experimental results.

\section{References}

This article references 42 other publications.

1. Lamoureux, N.; Paillard, C.-E. Shock Waves 2003, 13, 57-68

2. Metghalchi, M.; Keck, J. C. Combust. Flame 1980, 38, 143- 154

3. Hassan, M. I.; Aung, K. T.; Kwon, O. C.; Faeth, G. M. J. Propulsion Power 1998, 14, 479- 488

4. Hassan, M. I.; Aung, K. T.; Faeth, G. M. Combust. Flame 1998, 115, 539- 550

5. Huzayyin, A. S.; Moneib, H. A.; Shehatta, M. S.; Attia, A. M. A. Fuel 2008, 87, 39- 57

6. Tahtouh, T.; Halter, F.; Mounaïm-Rousselle, C. Combust. Flame 2009, 156, 1735-1743

7. Egolfopoulos, F. N.; Zhu, D. L.; Law, C. K. Proc. Combust. Inst. 1990, 23, 471- 478

8. Vagelopoulos, C. M.; Egolfopoulos, F. N.; Law, C. K. Proc. Combust. Inst. 1994, 25, 1341- 1347

9. Davis, S. G.; Law, C. K. Combust. Sci. Technol. 1998, 140, 427- 449

10. Vagelopoulos, C. M.; Egolfopoulos, F. N. Proc. Combust. Inst. 1998, 27, 513- 519

11. Dong, Y.; Vagelopoulos, C. M.; Spedding, G. R.; Egolfopoulos, F. N. Proc. Combust. Inst. 2002, 29, $1419-1426$

12. Jomaas, G.; Zheng, X. L.; Zheng, D. L.; Zhu, D. L.; Law, C. K.; Smith, D.; Aggarwal, S. Proc. Combust. Inst. 2005, 30, 193- 200

13. De Goey, L. P. H.; Van Maaren, A.; Quax, R. M. Combust. Sci. Technol. 1993, 92, 201- 207

14. Van Maaren, A.; Thung, D. S.; De Goey, L. P. H. Combust. Sci. Technol. 1994, 96, 327- 344

15. Dyakov, I. V.; Konnov, A. A.; De Ruyck, J.; Bosschaart, K. J.; Brock, E. C. M.; De Goey, L. P. H. Combust. Sci. Technol. 2001, 172, 81- 96

16. Konnov, A. A.; Dyakov, I. V.; De Ruyck, J. Exp. Thermal Fluid Sci. 2003, 27, 379- 384

17. Bosschaart, K. J.; De Goey, L. P. H. Combust. Flame 2004, 136, 261- 269

18. Kishore, V. R.; Duhan, N.; Ravi, M. R.; Ray, A. Exp. Thermal Fluid Sci. 2008, 33, 10- 16

19. Warnatz, J. Proc. Combust. Inst. 1984, 20, 845-856There is no corresponding record for this reference.

20. Hirasawa, T.; Sung, C. J.; Joshi, A.; Yang, Z.; Wang, H.; Law, C. K. Proc. Combust. Inst. 2002, 29, 1427- 1434

21. Liao, S. Y.; Jiang, D. M.; Cheng, Q. Fuel 2004, 83, 1247- 1250

22. Huang, Z.; Zhang, Y.; Zen, K.; Liu, B.; Wang, Q.; Jiang, D. Combust. Flame 2006, 146, 302- 311

23. Yu, G.; Law, C. K.; Wu, C. K. Combust. Flame 1986, 63, 339-347

24. Halter, F.; Chauveau, C.; Djebaïli-Chaumeix, N.; Gökalp, I. Proc. Combust. Inst. 2005, 30, 201- 208

25. Coppens, F. H. V.; De Ruyck, J.; Konnov, A. A. Combust. Flame 2007, 149, 409- 417

26. Hu, E.; Huang, Z.; He, J.; Jin, C.; Zheng, J. Int. J. Hydrogen Energy 2009, 34, 4876- 4888

27. Hermanns, R. T. E.; Konnov, A. A.; Bastiaans, R. J. M.; de Goey, L. P. H.; Lucka, K.; Kohne, H. Fuel 2010, 89, 114- 121 
28. Lewis, B.; Von Elbe, G. Combustion, Flames and Explosion of Gases, 2nd ed.; Academic Press, New York, 1961

29. Shin, S. S.; Vega, E. V.; Lee, K. Y. Combust., Expl., Shock Waves 2006, 42, 715- 722

30. Tahtouh, F.; Halter, F.; Samson, E.; Mounaïm-Rousselle, C. Int. J. Hydrogen Energy 2009, 34, 8329- 8338

31. Buda, F.; Bounaceur, R.; Warth, V.; Glaude, P. A.; Fournet, R.; Battin-Leclerc, F. Combust. Flame 2005, 142, 170- 186

32. Gülder, Ö.L.West Coast International Meeting \& Exposition, San Diego, CA, 1984; SAE Technical Paper, SAE 841000

33. Baulch, D.; Bowman, C.; Cobos, C.; Cox, R.; Just, T.; Kerr, J.; Pilling, M.; Stocker, D.; Troe, J.; Tsang, W.; Walker, R.; Warnatz, J. J. Phys. Chem. Ref. Data 2005, 34, 757- 1397

34. Tsang, W.; Hampson, R. F. J. Phys. Chem. Ref. Data 1986, 15, 1087

35. Barbé, P.; Battin-Leclerc, F.; Côme, G. M. J. Chim. Phys. 1995, 92, 1666- 1692

36. Fournet, R.; Baugé, J. C.; Battin-Leclerc, F. Int. J. Chem. Kinet. 1999, 31, 361- 379

37. Dagaut, P.; Cathonnet, M.; Boettner, J. Int. J. Chem. Kinet. 1991, 23, 437- 455

38. Kee, R. J.; Ruplay, F. M.; Miller, J. A. Sandia Laboratories Report S 89-8009B, 1993

39. Muller, C.; Michel, V.; Scacchi, G.; Côme, G. M. J. Chem. Phys. 1995, 92, 1154

40. Benson, S. W. Thermochemical Kinetics, 2nd ed.; Wiley: New York, 1976

41. Wang, H.; Frenklach, M. Combust. Flame 1996, 96, 163- 170

42. Konnov, A. A.; Barnes, F. J.; Bromly, J. H.; Zhu, J. N.; Zhang, D. Combust. Flame 2005, 141, 191199 